\title{
Bibliometric and social network analysis in scientific research on precision agriculture
}

\author{
José Luis Aleixandre-Tudó, Lourdes Castelló-Cogollos, José Luis Aleixandre* and \\ Rafael Aleixandre-Benavent
}

Precision agriculture (PA) is used to improve agricultural processes. A better understanding of $P A$ as well as the evolution of the research status through the available literature are reported and discussed in this study. The Web of Science (WoS) was used to obtain the research records under study. Indicators of scientific productivity, collaboration between countries and research impact were evaluated through a social network analysis. The keywords included in the publications and subject areas under which the research was published were also evaluated through subject analysis. A total of 2027 articles were analysed from 1994 to 2014. The most productive journals were 'Computers and Electronics in Agriculture' $(n=191)$ and 'Precision Agriculture' $(n=110)$. The most frequent keywords were 'management' $(n=243)$, 'yield' $(n=231)$, 'soil' $(n=198)$ and 'variability' $(n=190)$. The collaboration network showed the United States occupying a central position, in combination with some leading countries such as Brazil, Germany, People's Republic of China, Canada, Australia and Spain. A steady increase in PA research was identified during the last decade, which was even more sharp between 2010 and 2014. The increased importance of PA research has recently led to the birth of specific journals such as Precision Agriculture. The increasing number of journals that publish articles related to the topics included in the WoS must also be considered. The network analysis identified a number of developed countries in the hotspot of international collaboration.

Keywords: Bibliometrics, precision agriculture, research collaboration, scientific analysis, social network.

THE term 'precision agriculture' (PA) defines a farm management approach where the decision making relies on information-based knowledge. Each step of the production cycle is designed to improve the agricultural process using precision management techniques. Both agricultural production and profitability are optimized with the corresponding PA management approach. Costeffectiveness and environmental benefits are achieved due to the reduced use of inputs (energy, water, machinery, fertilizers, etc.). Increased yields and better quality are thus more likely to be the source of profitability ${ }^{1}$.

PA is also defined as an improved agricultural management production strategy. However, it also takes into

\footnotetext{
Jose Luis Aleixandre-Tudo is in the Department of Viticulture and Oenology, Stellenbosch University, Private Bag X1, Matieland 7602, South Africa; Lourdes Castelló-Cogollos is in the Departamento de Sociologia y Antropología Social, Universidad de Valencia, UISYS (CSIC-Universidad de Valencia), Blasco Ibañez 13, 46022, Spain; Jose Luis Aleixandre is in the Instituto de Ingeniería de Alimentos para el Desarrollo (IIAD), Universidad Politécnica de Valencia, Camino de Vera s/n, 46022, Spain; Rafael Aleixandre-Benavent is in the Ingenio (CSIC-UPV), UISYS (CSIC-Universidad de Valencia), Blasco Ibañez 13, 46022, Spain.

*For correspondence. (e-mail: jaleixan@tal.upv.es)
}

account the considerable variation (even within very short distances) that influences the potential productivity of agricultural activity ${ }^{2,3}$. The development of PA is, for instance, in response to the variable intrinsic ability of an agricultural land to produce outputs ${ }^{4,5}$. Recent available techniques are of major importance in PA, including a number of systems such as global positioning system (GPS), or geographical information systems (GIS), in combination with remote sensing and/or crop-yield monitoring.

Research and applications of PA in the sugarcane industry were undertaken in Australia during the second part of the 1990s (refs 6, 7). Unfortunately, collapse in the price of sugar worldwide, among other factors, led to a low adoption of the technology. In the meantime, a gain in growing experience through research has been accumulated $^{5}$. In the specific case of Australia, apart from the predominant focus on the grain industry, an increasing interest in other related industries such as wine, cotton and other cropping industries was also noticed ${ }^{8}$.

Interesting reviews on the state-of-the-art of precision viticulture (PV) have been published ${ }^{2,9,10}$. In the studies by Bramley and Hamilton ${ }^{11,12}$, yield crop maps were collected from different vineyards sites and over a number of 
vintages. The authors reported stable patterns over time in the variation of grape yields despite clear vintage-to-vintage effect ascribed to yearly varying weather patterns.

In addition, a recent review of the current situation of broad PA worldwide has been published ${ }^{13}$. The application of PA in different industries, including potato, sugar beet, wheat, barley, corn, soybean, oats, rice, sorghum and cotton has been reported ${ }^{13}$. The commercial use of PA for winegrapes ${ }^{9,14}$, citrus ${ }^{15,16}$, banana ${ }^{17}$, tea and date palm $^{18}$ production has also been extensively reported. Improvements in the management of the tobacco and olives $^{19}$, tomato ${ }^{20}$, apple ${ }^{21}$, kiwifruit ${ }^{22}$ and sugarcane ${ }^{7,23}$ have also been identified.

The profitability when PA management was applied has been the main focus of some economic studies ${ }^{24}$. These studies identified a limited difference on the payoffs despite a large deviation from the optimum agricultural decision $^{25}$. Also, it has been reported that the possible benefits of PA application in the UK cereal industry are defined by the interactions between a number of variables, including farm size, cost of PA equipment and increase in the annual yield required to balance these $\operatorname{costs}^{26}$

On the other hand, the use of remote imaging with the possibility of incorporating yield mapping has received the greatest attention in $\mathrm{PV}^{27}$. The main factor here is the sequential harvesting strategy defined based on yield/quality criteria needed to account for the observed variation $^{28}$.

The use of published studies to analyse the research trends through bibliometric approaches is receiving increasing attention. This is because the main indicators of scientific research as well as its progression over time are evaluated ${ }^{29}$. Even though research on PA is gaining public importance, scientometric studies based on published research on this topic are currently not available. The contribution to an extensive understanding of the scientific knowledge in PA, as well as the analysis of its evolution through published papers included in the Web of Science (WoS) database is thus the main aim of this study.

\section{Methods}

The Science Citation Index-Expanded (SCIE) database was used in this study. The search strategy included the terms 'precision agriculture' or 'precision farming'. We used these keywords as they gave more satisfactory results. For better comprehension of the results, the topic field was used to conduct the search. The title, abstract and keywords were thus included within the topic field. The inclusion of quotation marks was done to guarantee enhanced precision of the obtained records, e.g. all records containing the terms in the same order. An individual revision of the items was performed to ensure their relevance. The analysis was performed including the articles published in the period from 1994 to 2014 (21 years). Only original papers and reviews were selected as research contributions. Conference abstracts, book reviews, bibliographical articles, letters, editorials, news and reprints were therefore not included in the study.

The evolution of published papers per year and distribution of papers per journal, keywords, WoS subject categories and countries were considered as indicators of scientific productivity. The number of citations, ratio citations per article as well as impact factor and quartile in Journal Citation Reports (JCR) subject categories were evaluated as the main indicators of impact. The most cited papers were also reported. Only the citations extracted from the WoS database received by the articles and reviews during the period of analysis were taken into account. The 2014 edition of the JCR was consulted to obtain the impact factor data. The number of cooccurrences among countries was studied through a social network analysis (SNA). The relationships and flows among people, groups, organizations or countries were mapped measuring a pairwise combination among countries for each paper, which may also be present in other papers. The nodes in the network include people and groups, while the links establish relationships or flows between the nodes.

The assigned keywords and subject categories of journals included in the JCR were evaluated through subject analysis. The number of co-occurrences between keywords (cowords) was evaluated using SNA. A cooccurrence indicates combinations of keyword pairs found repeated within the papers obtained. The application of SNA to co-word analysis provides network graphs showing a visual representation of the strongest associations between the keywords and thus concepts included in the scientific papers ${ }^{30}$. SNA has also been used to evaluate knowledge in other fields such as environmental science $^{31}$, tsunamis ${ }^{32}$, wine and health ${ }^{33}$, among others.

The software Pajek ${ }^{34}$ was used to generate and graphically visualize the networks. The software VOSViewer was used to generate the international collaboration network of countries. A threshold or minimum of relations to appear in the networks was applied in order to correctly visualize the networks. Different thresholds were later specified based on the results obtained.

\section{Results}

The number of articles obtained from the WoS during the period of analysis was 2027. As can be observed in Figure 1, the number of scientific articles published has increased since 1994. The most prominent growth has been observed in the last decade, since $75.8 \%$ of the papers was published.

Table 1 presents journals publishing more than 20 papers. The table also includes the number of citations received and the ratio citations per paper as well as 
impact factor, the WoS subject category, including quartile and ranking within the category. The journals with the highest productivity were Computers and Electronics in Agriculture $(n=191)$, Precision Agriculture $(n=110)$, Applied Engineering in Agriculture $(n=80)$ and Agronomy Journal $(n=52)$. When the number of citations was evaluated Computers and Electronics in Agriculture $(n=3.730)$ ranked first, followed by Remote Sensing of Environment $(n=2.240)$, Geoderma $(n=1.516)$ and Agronomy Journal $(n=1389)$. Remote Sensing of Environment had higher impact factor ( $\mathrm{IF}=5.103)$, followed by European Journal of Agronomy (IF = 2.800), Agricultural Systems (IF = 2.504), Fields Crop Research (IF = 2.4746), and Soil and Tillage Research (IF = 2.367). Majority of the above-mentioned journals are within the first or second quartile in the subject category of JCR, excluding Applied Engineering in Agriculture, Communications in Soil Science and Plant Analysis, Transactions of the ASABE, Revista Brasileira de Ciencia do Solo and Spectroscopy and Spectral Analysis that rank in the third or fourth quartile.

Table 2 shows the most common keywords as well as their annual evolution. The most frequent keywords are 'management' $(n=243)$, 'yield' $(n=231)$, 'soil' $(n=198)$ and 'variability' $(n=190)$. For the majority of the keywords an increase in the frequency of use was observed especially since the 2000 s. Keywords that significantly increased in frequency were 'systems' and 'vegetation indexes'. Others only appear during the period 2000-2007: 'electrical conductivity', 'electromagnetic induction', 'management zones', 'leaf-area index', 'chlorophyll content', 'hyperspectral' and 'scale'.

Table 3 provides the number of research indicators, including the most productive subject categories, the most common keywords assigned to the articles and the most prolific journals per subject category. The subject category agriculture, 'multidisciplinary' $(n=530)$ appears first, where the most common keywords are 'yield' $(n=76)$, 'management' $(n=63)$ and 'systems' $(n=54)$.

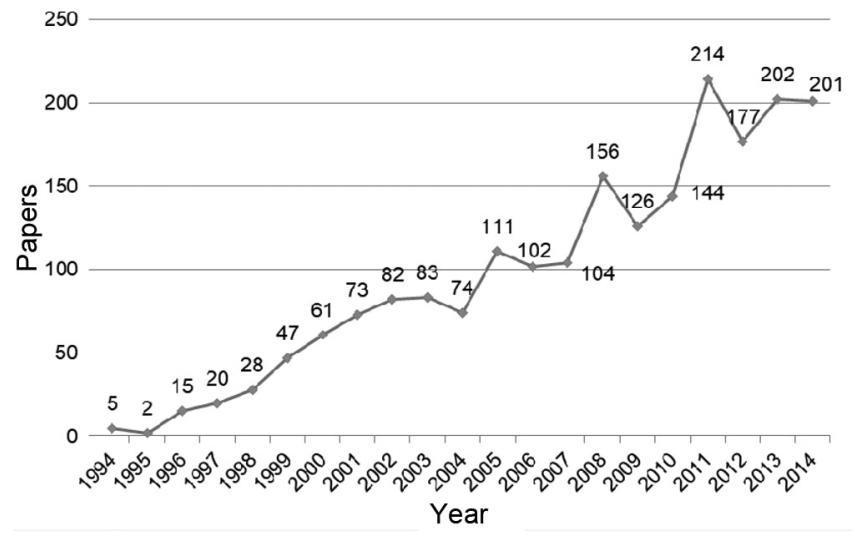

Figure 1. Annual evolution of published papers.
The most prolific journals within this subject category were Computers and Electronics in Agriculture $(n=191)$, Precision Agriculture $(n=110)$ and Biosystems Engineering $(n=32)$. The second most frequent subject catetory was 'agronomy' $(n=363)$, whose most frequent keywords were 'yield' $(n=54)$, 'management' $(n=52)$ and 'soil' $(n=52)$. The most prolific journals were Agronomy Journal, Fields Crop Research and European Journal of Agronomy. Three other subject category with more than 100 records were 'agricultural engineering' ( $n=327$; with 'sensors', 'yield' and 'global positioning system' as the most frequent keywords), 'soil science' ( $n=298$, with keywords 'spatial variability', 'management' and 'variability') and 'computer science interdisciplinary applications' ( $n=194$, with keywords 'systems', 'yield' and 'global positioning system'). Other significant subject categories with more than 100 published papers include 'remote sensing' $(n=141)$, with the most frequent keywords being 'vegetation indexes' $(n=50)$, 'reflectance' $(n=30)$ and 'chlorophyll content' $(n=23)$; 'plant sciences' $(n=131)$ and 'environmental sciences' $(n=122)$.

Table 4 shows 21 research publications that received more than 100 citations. The most cited article, 'Hyperspectral vegetation indices and novel algorithms for predicting green LAI of crop canopies was published in Remote Sensing of Environment in 2004. This paper received 407 citations. The second paper with the highest number of citations $(n=383)$ was published in 2002 in the same journal. The third most cited paper, with more than 300 citations, was published by Cassman in 1999 in Proceedings of the National Academy of Sciences of the United States of America. Three other papers received more than 200 citations and 15 papers more than 100 citations. Almost $50 \%$ of the most cited papers was published in two journals: Remote Sensing of Environment and Computers and Electronics in Agriculture.

Figure 2 shows the network of collaboration among countries. The sphere size, number of publications, connecting lines and papers published in collaborations are proportional. A central position is occupied by the US with other leading countries such as Brazil, Germany, People's Republic of China, Canada, Australia and Spain. Collaboration was particularly more among the US and People's Republic of China $(n=37)$, Canada $(n=28)$, Germany $(n=16)$ and South Korea $(n=15)$. Other collaborations were established between Germany and China $(n=20)$, the US and Italy $(n=14)$ as well as Australia and Spain $(n=12)$.

Figure 3 shows the keywords most frequently associated with these countries. In this figure, the number of articles and the number of keywords in papers published by each country are proportional to the sphere size and thickness of lines connecting the spheres respectively. The US has a wide variety of keywords (yield, corn, management and models, among others) followed by Brazil 


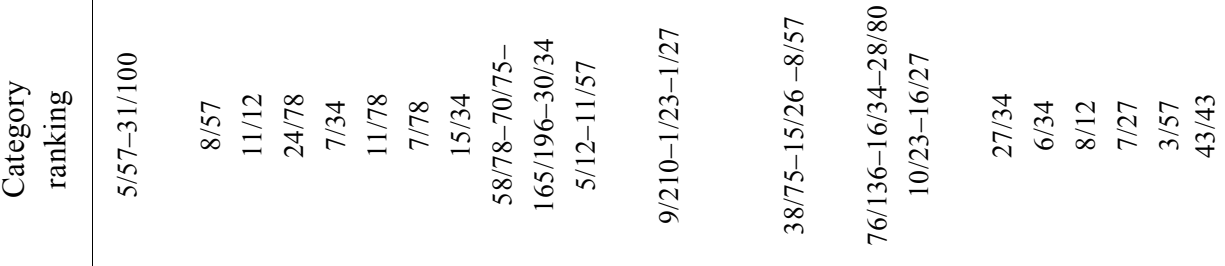

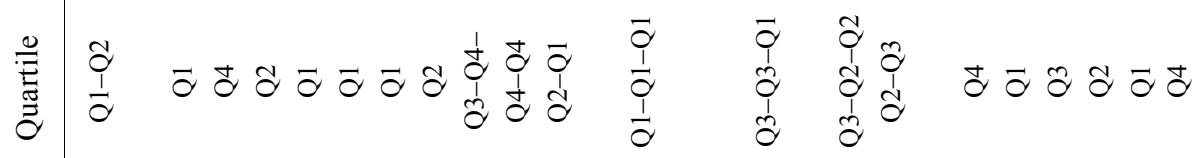

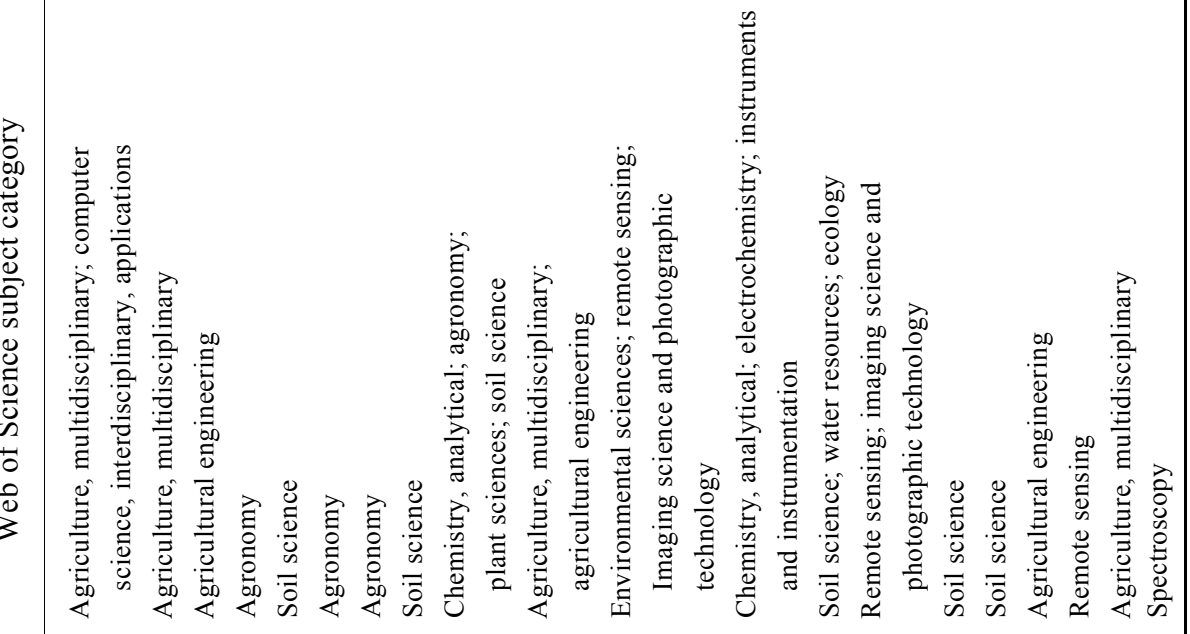

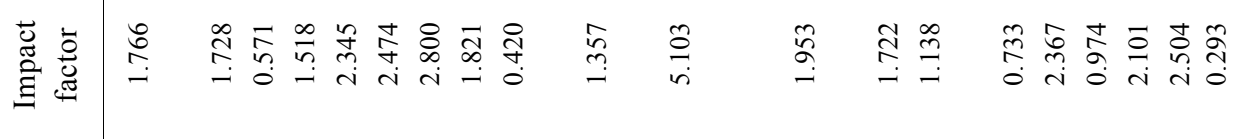

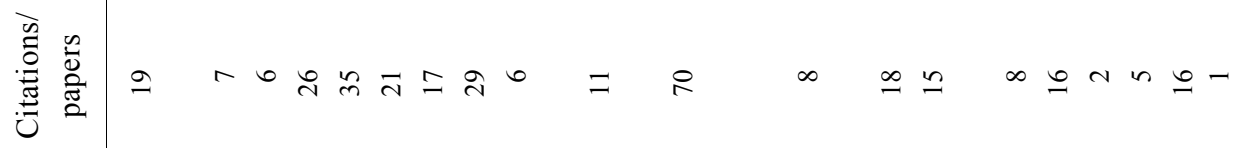

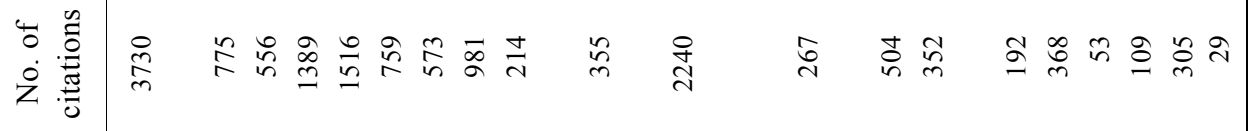

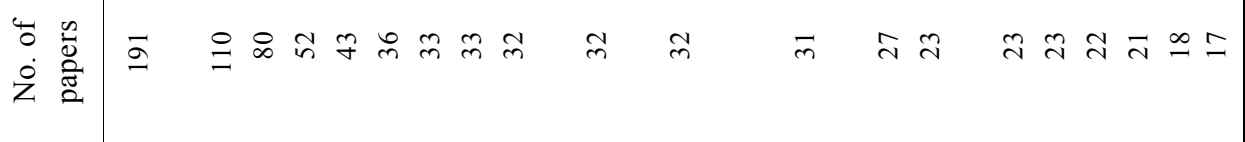
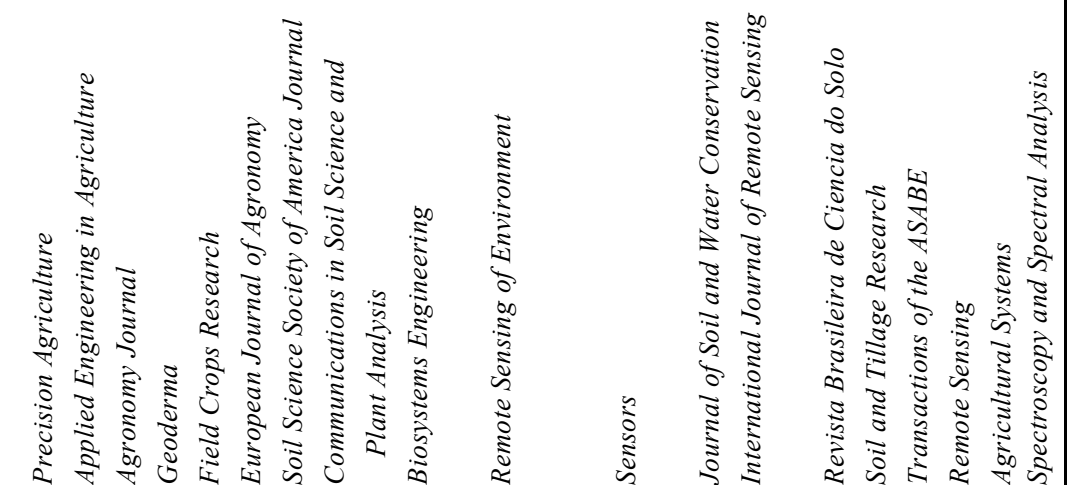
GENERAL ARTICLES

Table 2. Total number of published articles, including the most frequent keywords by time period

\begin{tabular}{|c|c|c|c|c|}
\hline Keyword & 1994-2000 & $2000-2007$ & 2008-2014 & Total \\
\hline Management & 18 & 70 & 155 & 243 \\
\hline Yield & 16 & 72 & 143 & 231 \\
\hline Soil & 20 & 76 & 102 & 198 \\
\hline Variability & 4 & 67 & 119 & 190 \\
\hline Wheat & 8 & 52 & 120 & 180 \\
\hline Spatial variability & 16 & 55 & 103 & 174 \\
\hline Nitrogen & 11 & 65 & 90 & 166 \\
\hline Systems & 7 & 35 & 118 & 160 \\
\hline Models & 10 & 54 & 90 & 154 \\
\hline Corn & 12 & 54 & 86 & 152 \\
\hline Remote sensing & 11 & 48 & 93 & 152 \\
\hline Vegetation indexes & 3 & 24 & 97 & 124 \\
\hline Field & 10 & 35 & 73 & 118 \\
\hline Reflectance & 3 & 40 & 74 & 117 \\
\hline Geostatistics & 9 & 41 & 60 & 110 \\
\hline Crops & 1 & 36 & 68 & 105 \\
\hline Sensors & 4 & 28 & 65 & 97 \\
\hline Classification & 4 & 31 & 52 & 87 \\
\hline Soil properties & 5 & 28 & 51 & 84 \\
\hline Global positioning system & 16 & 26 & 36 & 78 \\
\hline Prediction & 2 & 23 & 52 & 77 \\
\hline Growth & 3 & 32 & 41 & 76 \\
\hline Electrical conductivity & & 22 & 53 & 75 \\
\hline Site-specific management & 6 & 23 & 43 & 72 \\
\hline Water & 4 & 30 & 37 & 71 \\
\hline Geographic information system & 13 & 23 & 34 & 70 \\
\hline Electromagnetic induction & & 26 & 38 & 64 \\
\hline Management zones & & 18 & 45 & 63 \\
\hline Leaf-area index & & 16 & 45 & 61 \\
\hline Spectral reflectance & 2 & 15 & 44 & 61 \\
\hline Quality & 2 & 17 & 41 & 60 \\
\hline Water content & 1 & 25 & 33 & 59 \\
\hline Phosphorus & 3 & 17 & 33 & 53 \\
\hline Soil electrical conductivity & 1 & 18 & 34 & 53 \\
\hline Chlorophyll content & & 9 & 43 & 52 \\
\hline Vegetation & 2 & 12 & 38 & 52 \\
\hline Hyperspectral & & 9 & 42 & 51 \\
\hline Canopy & 1 & 13 & 36 & 50 \\
\hline Canopy reflectance & 1 & 12 & 36 & 49 \\
\hline Kriging & 5 & 16 & 26 & 47 \\
\hline Scale & & 16 & 31 & 47 \\
\hline Simulation & 6 & 15 & 26 & 47 \\
\hline Fertilizers & 4 & 22 & 20 & 46 \\
\hline Grain-yield & 2 & 13 & 30 & 45 \\
\hline Tillage & 4 & 26 & 15 & 45 \\
\hline Cotton & 1 & 18 & 25 & 44 \\
\hline Leaves & 2 & 13 & 29 & 44 \\
\hline Plants & 3 & 12 & 29 & 44 \\
\hline Moisture & 3 & 13 & 26 & 42 \\
\hline
\end{tabular}

(geostatics and yield), People's Republic of China and Spain (vegetation indexes and remote sensing) and Canada (yield and management).

Figure 4 shows the evolution of the network of cowords over three periods. The proportionality between the sphere sizes and the articles, including the keywords also applies to this figure. The same proportionality criterion is maintained for the thickness of the connecting lines and the number of publications with two keywords. In the first period (1994-2000), a threshold of two co- occurrences was applied, thus consisting of a network with 54 keywords. The keyword 'soil' is centrally located and associated with 16 other keywords. Other words that act as intermediaries with less intensity (in partnership with five other keywords) are 'geostatics', 'spatial variability', 'management', 'global positioning system' and 'geographic information system'. In the second period (2000-2007), applying a threshold of 5 co-occurrences, the network contained 57 keywords with several of them having central roles and intermediation. These are 


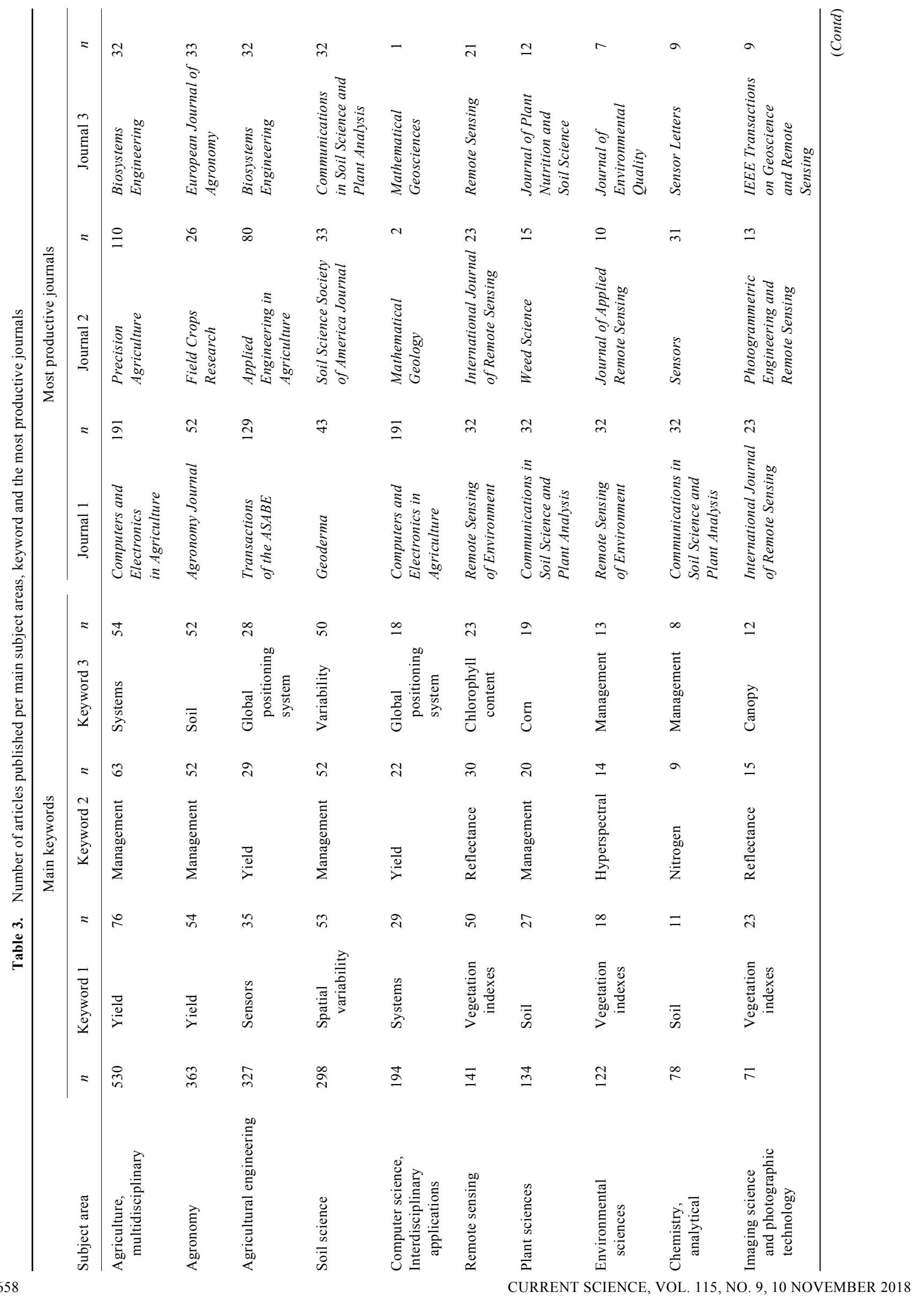




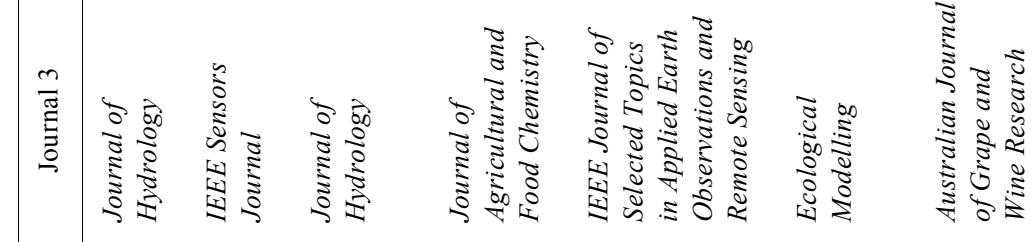

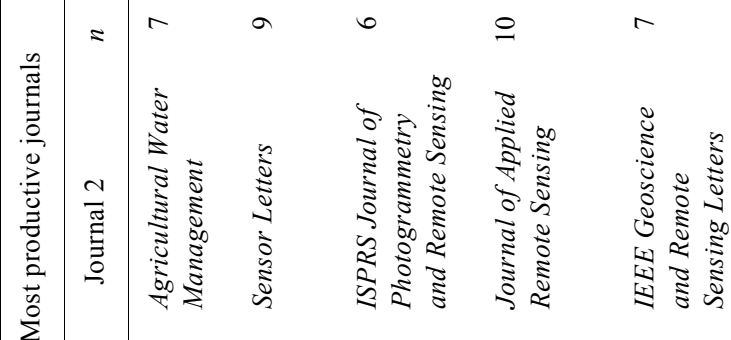

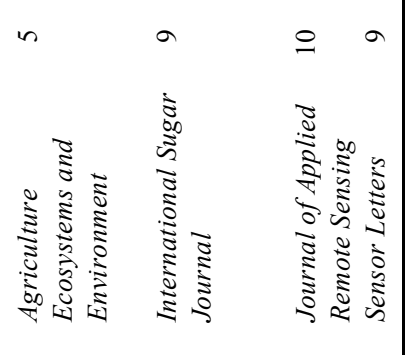

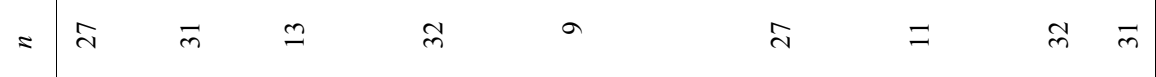

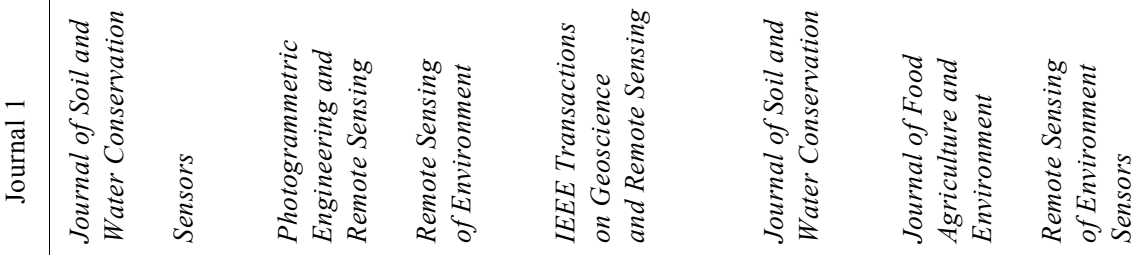

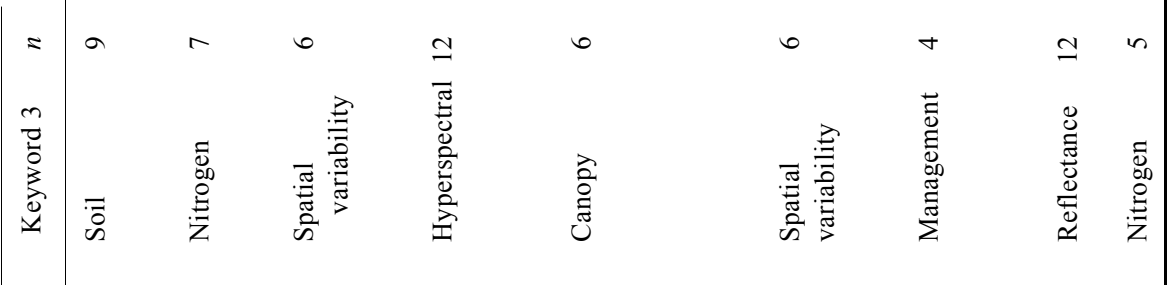

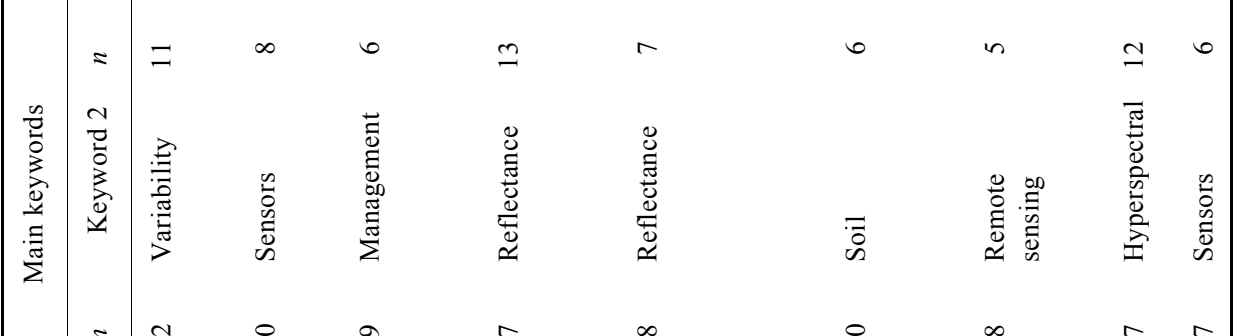

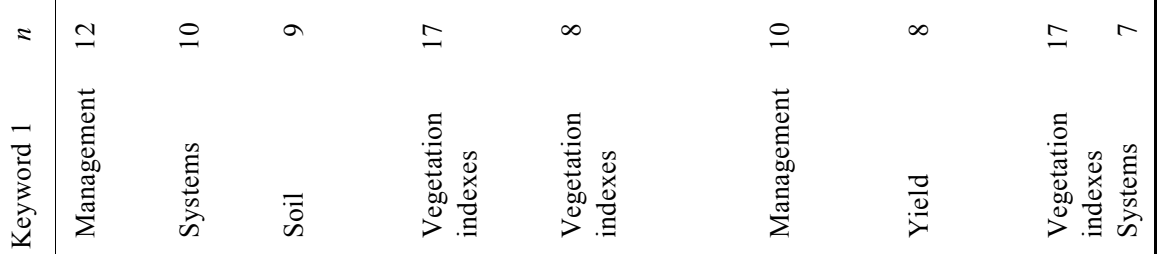

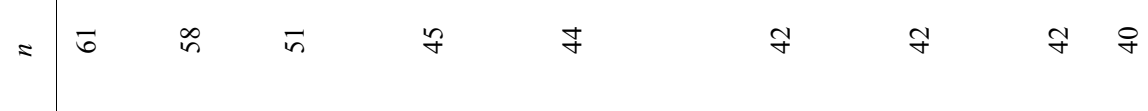

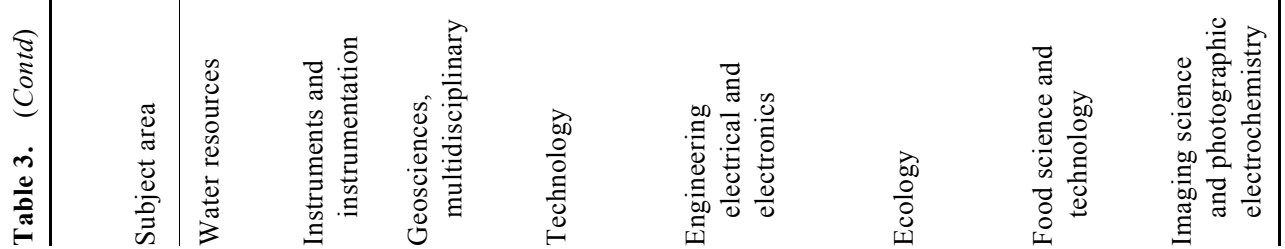




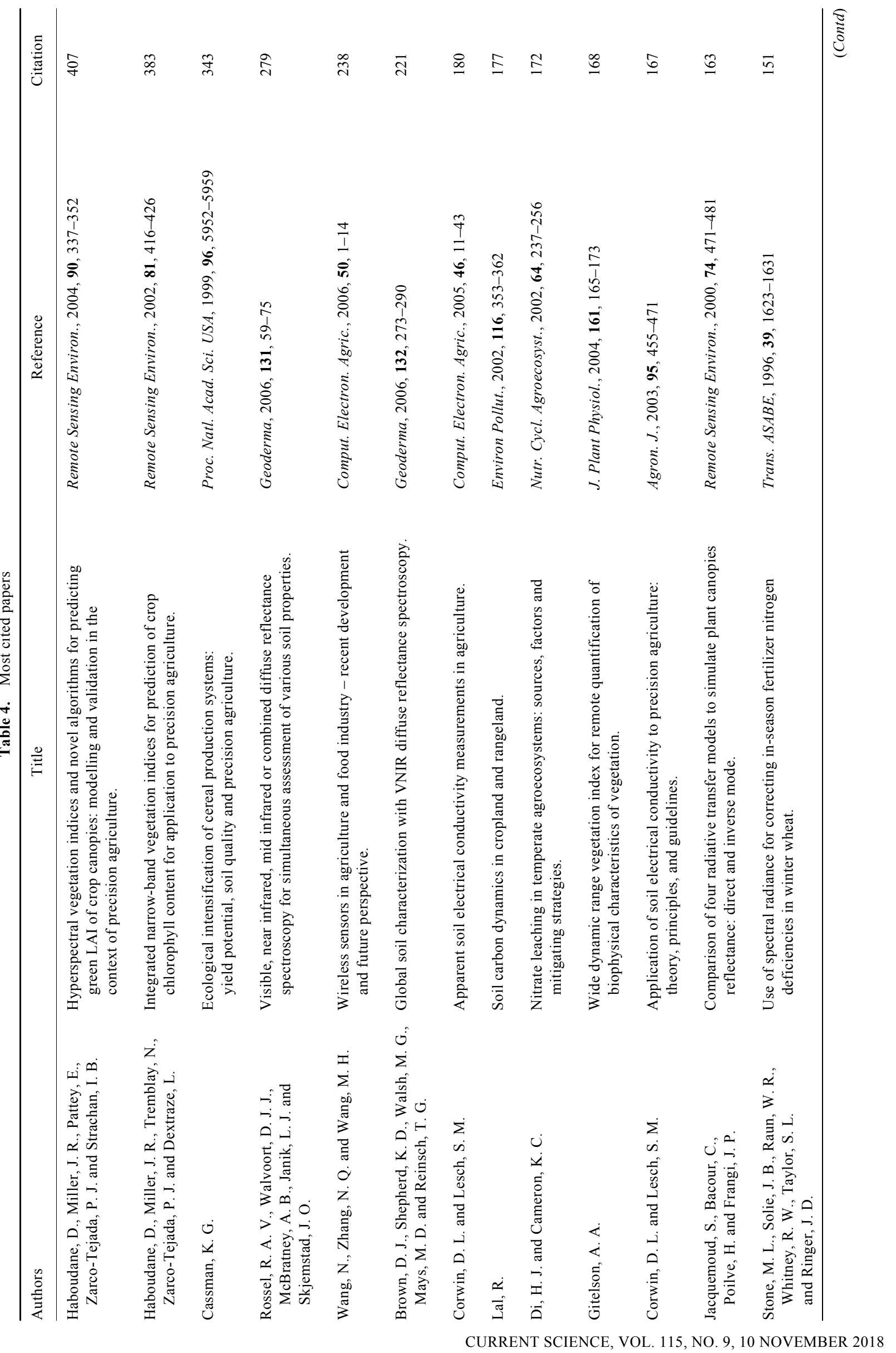




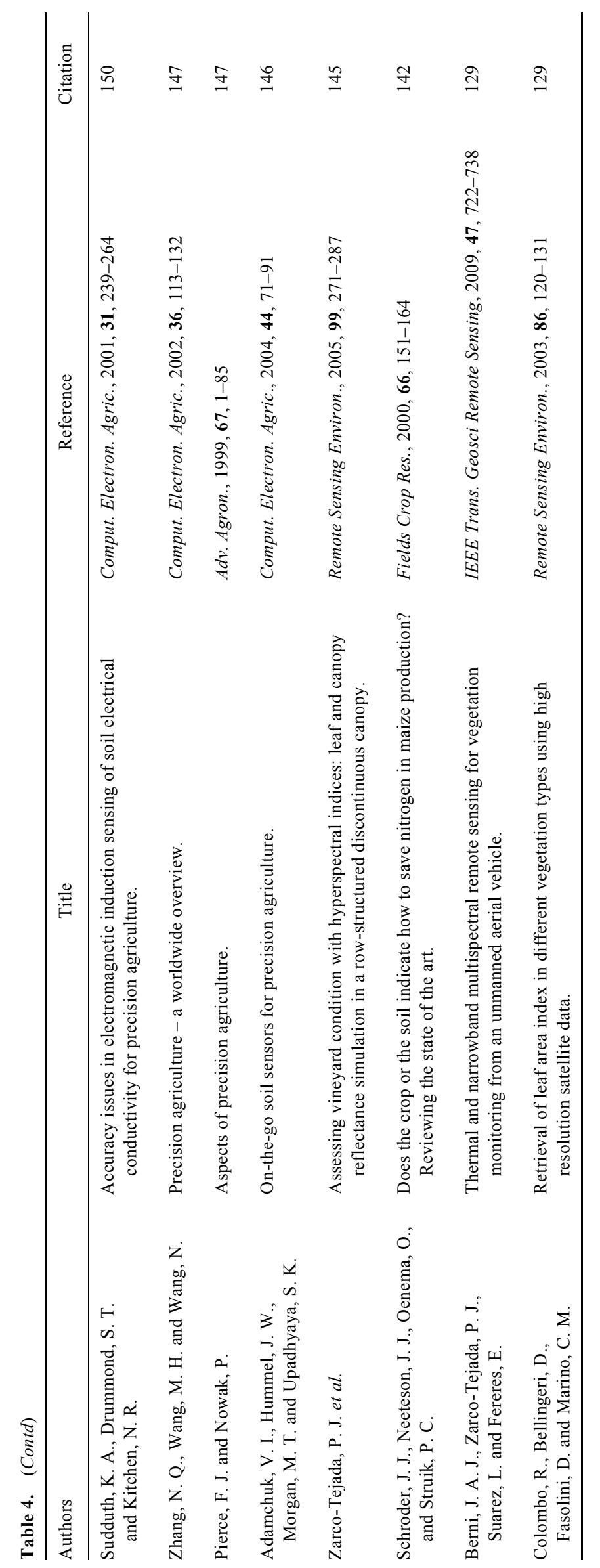




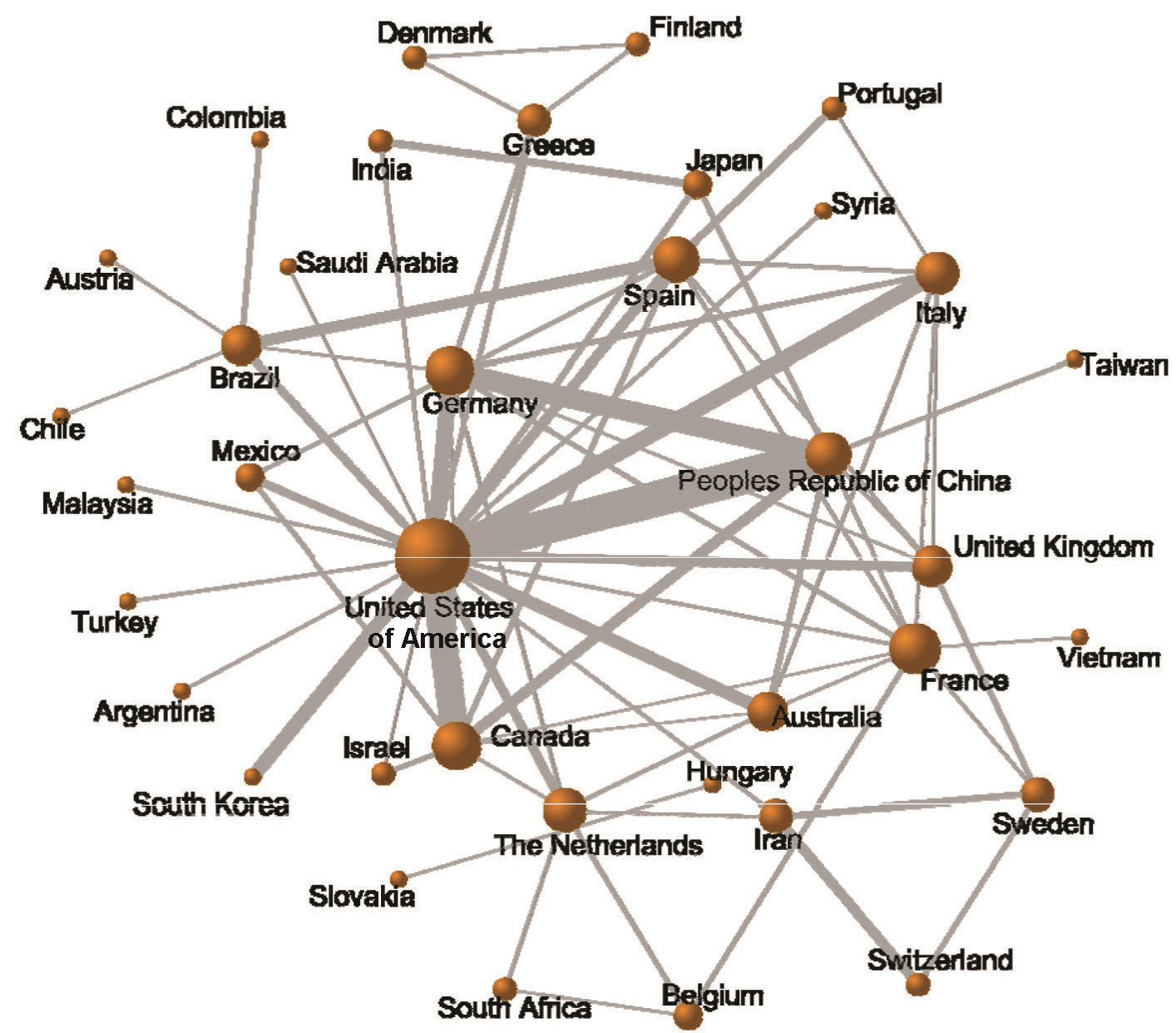

Figure 2. Network of collaboration among countries. The size of the spheres is proportional to the number of published papers per country. Only countries with five or more papers are represented.

'variability', 'spatial variability', 'nitrogen', 'yield' and 'corn', among others. In the third period (2008-2014), with a threshold of 10 co-occurrences, the network of cowords included 48 keywords; new terms occurred with central position such as 'system' and 'reflectance'.

\section{Discussion}

The annual evolution of scientific articles, as well as the most productive journals, subject categories, productive countries and their international collaboration and also the most cited papers are reported in this study. The evolution of scientific knowledge on the topic through the most frequently used keywords and the co-words SNA is also shown. Through this study an enhanced level of cooperation between international communities is promoted due to the availability of information on PA with the establishment of a favourable environment for research networking, collaboration and debate.

Several studies are available in the literature that has used scientometric approaches to evaluate the knowledge status of a particular field or scientific topic. Some examples are: plant genetic resources ${ }^{35}$, biotechnology $y^{36,37}$, food and feed safety ${ }^{29}$, flow cytometry ${ }^{38}$, environmental marketing ${ }^{39}$, production of bioenergy from biomass ${ }^{40}$, the effects of wine on health ${ }^{33}$ and soil contamination ${ }^{41}$. However, we found only one paper from Portugal using SNA to measure and map scientific knowledge in $\mathrm{PA}^{42}$. A number of databases are available nowadays, which have helped researchers perform studies on a wide variety of disciplines and topics. For example, in the WoS, using the WoS database, it is possible to perform bibliometric analysis taking into account citations received and journal impact factors. On the other hand, several software programs allow the visualization of the relationship among data by means of exploring portions of the articles like titles, keywords and abstracts ${ }^{43}$.

The annual evolution of the number of published articles shows three well-differentiated periods. The first one extends to early 2000 , with a moderate increased production of 41 papers on an average per year. In 1994, only one paper was published with near 100 papers per year in 2000. The second period is from 2001 to 2007 with 


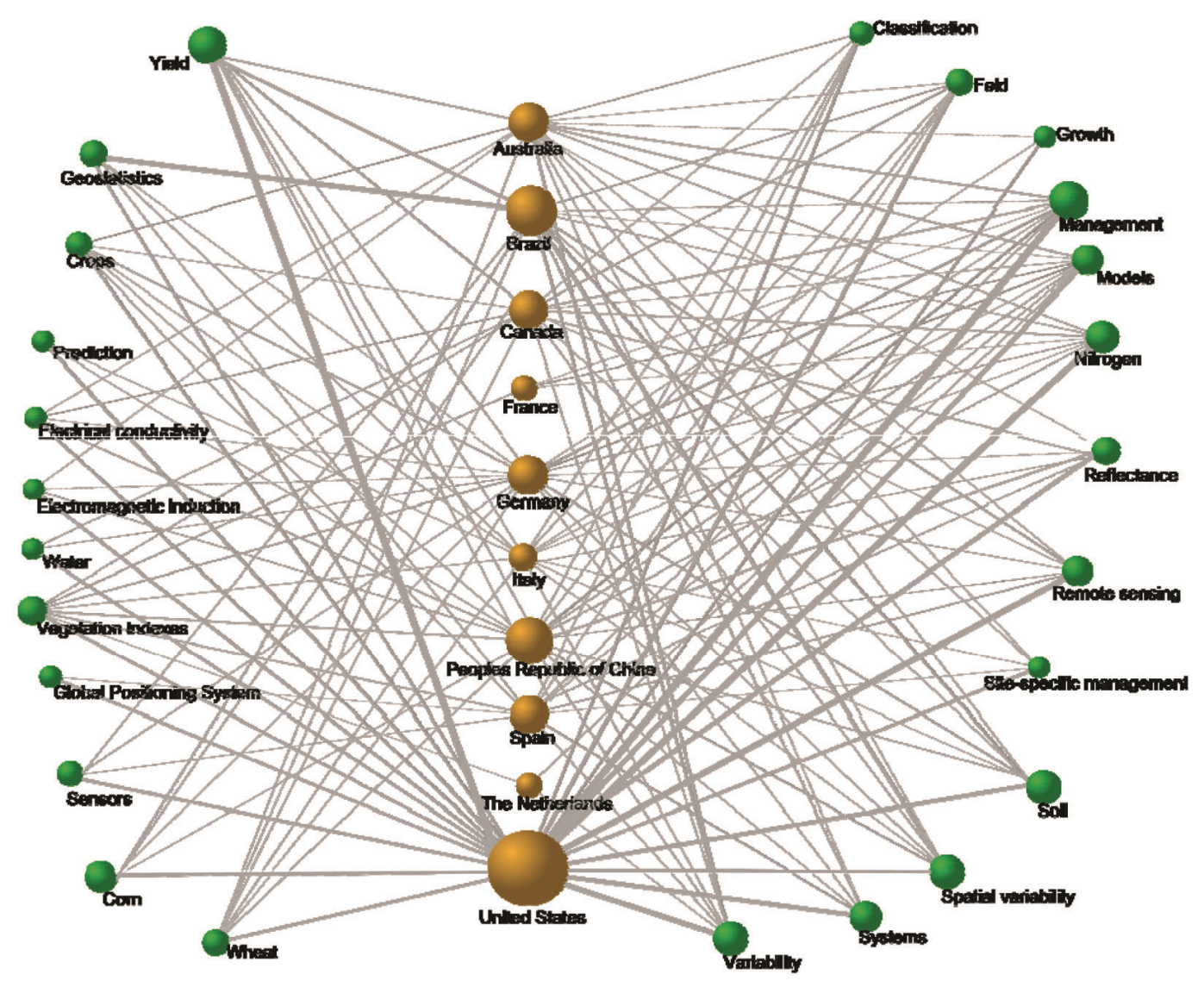

Figure 3. Network of main productive countries and most frequent keywords. The size of the spheres is proportional to the number of papers published including the keywords by each countries and to the number of papers published per keyword.

similar growth, and with an average of 185 papers per year. It is in the third period (2008-2014) where maximum growth is seen, reaching 540 articles in 2014 , with an average of 435 papers per year. The increased productivity observed on PA is supported by the overall number of publications identified in this study. This growth has also been observed, from the bibliometric point of view, in other research areas such as agro-ecology ${ }^{44}$, soil contamination ${ }^{41}$ and wine and health ${ }^{33}$.

From its origins in the late 1980 s, PA was developed in contrast to mainstream agriculture and to traditional agricultural institutions and policies. In the nineties, the EU completely changed this situation with the introduction of organic farming support schemes, regulations and increasing involvement of state authorities on this topic (e.g. training, education, advice, information, research) ${ }^{45}$. In June 2014, the Joint Research Centre of the European Commission published a report entitled 'precision agriculture: an opportunity for EU farmers 2004-2020', where experts on the topic suggested the need to develop appropriate guidelines and implementation assistance, also highlighting that this should go together with the corresponding research and development studies that have to define, monitor and evaluate specific programmes and measurements. Sharing the acquired knowledge and expertise is thus encouraged and the state members are required to provide conclusions, advice and identify research gaps within this topic. In the US, the Alternative Farming Systems Information Center (AFSIC) is specialized in identifying resources regarding sustainable food systems and practices, and is supported by the United States Department of Agriculture with the objective of ensuring a sustainable future in agricultural practices and farming.

The increased importance of PA research in recent times has given birth to specific journals such us Precision Agriculture (Springer), available since 1999, but only included in the WoS from 2006. Before the foundation of Precision Agriculture, the European Conference on Precision Agriculture had been organized every alternate year and its proceedings have played a key role in documenting and communicating research results. In addition to the existing journals, the increasing number of journals that publish articles related to the topic included in the WoS must also be considered. For example, the number of journals included in the 'agriculture multidisciplinary' subject category has increased from 35 in 2008 to 56 in 2013. To this subject category belongs the journal in 


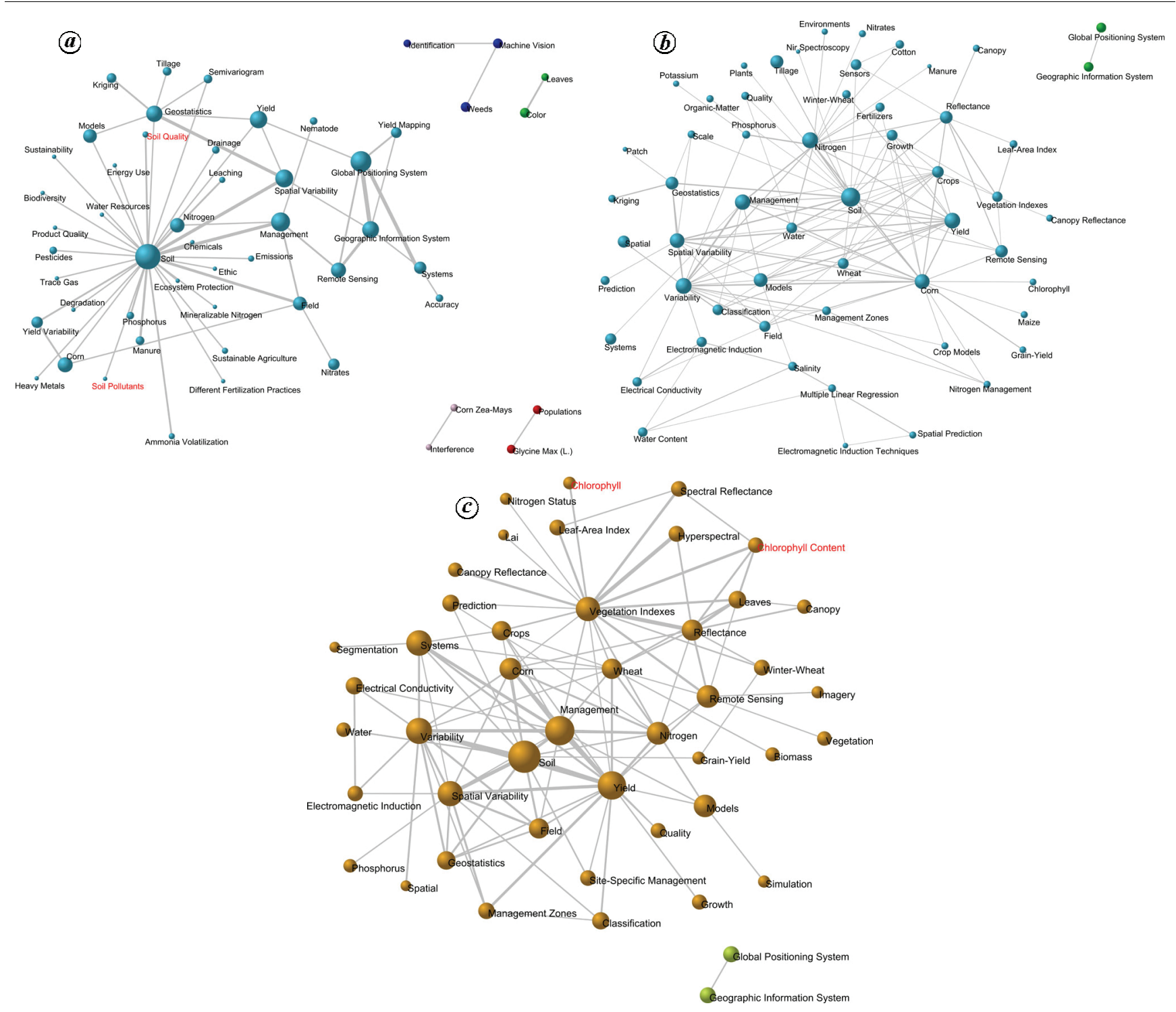

Figure 4. Network of co-words during: (a) 1994-2000; (b) 2001-2007; (c) 2008-2014.

which a larger number of articles and the highest number of citations have been identified, i.e. Computers and Electronics in Agriculture, although it also belongs to the category 'Computer sciences, interdisciplinary, and applications'. A similar pattern and increased number of edited journals can be observed in other categories such as 'agronomy' (from 49 journals included in 2008 to 79 in 2013), and to a lesser extent 'agricultural engineering' (from 9 journals included in 2008 to 12 in 2013) and 'soil science' (from 31 journals included in 2008 to 34 in 2013).

The keywords analysis has revealed the main issues addressed in the articles. Excluding generic keywords associated with agriculture like 'yield', 'soil' and 'field', it is observed that the most frequently treated aspects were 'management', 'variability', 'systems', 'models', 'remote sensing' and 'vegetation indexes'. Regarding technological aspects, papers included remote sensing, geostatics, sensors, global positioning system, electrical conductivity and geographic information systems, among others. In a previous publication where research activity in the 'agronomy' category of the WoS was studied ${ }^{15}$, the ranking of keywords used was similar to the present study with the exception of the first most frequently used keyword. In the above mentioned study it was 'yield', whereas in the present study, 'management' occupied the first place and 'yield' the second. In both studies 'soil' occupied the third place, 'wheat' the fifth and 'nitrogen' the seventh place. Not surprisingly, the most used keywords identified in this study were not used in the mentioned publication ${ }^{46}$.

Brazil, with the largest land area in South America, is making great use of geostatistics, as it allows the description and characterization of soil variables through a set of samples. Geostatistics has been used in Brazil, among other actions, for the prospection and evaluation of soil and 
deposits $^{40,47}$, mining geochemical exploration ${ }^{48}$, evaluation of solar resource ${ }^{49}$ and for assessing the effects of air contaminants on human health in industrialized areas ${ }^{50}$.

Considering at the subject categories (areas of research) and in accordance with the previous results, articles published in non-specific areas of agriculture, such as agriculture multidisciplinary, agronomy, agricultural engineering, soil science and plant science and in technological areas such as computer science, remote sensing, imaging science, photographic technology, among others, were identified. Thus technology plays an important role in the development of precision farming. There are several studies focusing on areas such as electronics, ecology, food science and technology and imaging and photographic sciences. This spread in subject categories suggests that PA is a research topic that further requires collaboration of other scientific areas from alternative disciplines.

The analysis of collaboration between countries shows that research on the topic is mainly performed in developed countries such as the US, Canada, Germany, Italy and Spain. There is noteworthy collaboration between the US and China, and partnership among developing countries such as South American and Asian countries. This geographical and economical distribution has also been noticed in topics such as agro-ecology ${ }^{44}$, soil contamination $^{41}$, and production of bioenergy from biomass ${ }^{51}$.

In terms of papers with more citations, a number of findings need to be highlighted. First, a large part of them deal with several aspects of soil (quality, conductivity, sensors, properties, carbon dynamics, etc.), vegetation indices and spectroscopy, among others. Secondly, the multidisciplinary nature of the journals publishing research studies on this topic has been identified. Finally, the importance of related issues to the environment, ecology, sensors, computers and electronics has also been observed.

\section{Conclusion}

Helpful insights in precision farming research have been identified in this study. Many themes such as the most promising subject areas, journals, topics and collaboration between countries have been evaluated and further discussed. On the basis of the research findings, some conclusions and recommendations for the key network players could be drawn. The research on PA had markedly increased during the last decade, more sharply between 2010 and 2014. The scientometric and SNA has the ability to provide useful information on the research direction in the field, similar to that observed in other new emerging fields, i.e. emerging technologies and processes. Therefore, addition of scientometric studies to the content analysis studies as well as literature reviews increases knowledge in the area. SNA enables us to identify the main traits on the evolution of PA using a net- work of co-words, as well as the leader countries in the area and their network of collaboration, and finally the main topics dealt with by each country.

Although estimating the importance of PA has not been widely reported in the past, we believe that such a study will have a great impact on the present and future discussions on PA. First, the status of PA research needs to be known in order to establish adequate policy practices by the policy-makers. It is also important to be aware of the current research in order for the private sector firms to position themselves against their competitors ${ }^{52}$.

\section{Limitations}

Our study has some limitations that need be addressed. First, bibliometric analysis was performed based on articles archived in WoS. The reason for using WoS instead of Scopus or Google Scholar was based on conclusions drawn in studies reported in the literature ${ }^{52,53}$. Second, in the early nineties, when PA had developed as a topic for scientific study, proceedings of the major PA conferences held in the US and Europe were an important source of research information. However, these have not been included in the present study because the ideas reported are often published in scientific journals. However, it is possible that many of these papers were never published in refereed journals because of the lack of viable venues for publication and, therefore, such research has not been analysed in our study. Third, also in the early nineties, there were other terms used for PA research, as 'sitespecific farming', 'spatial soil management' or 'smart farming'; so we could have missed a few records. Nevertheless, the terms used in our search have ensured greater accuracy in the obtained records.

\section{Future directions}

Future research could identify the networks of collaboration between researchers and institutions, allowing for the identification of groups of authors and/or institutions that currently make up the research front in this area and its main research topics, information that would be useful both to strengthen collaboration networks between the research teams working on similar or related topics, which indicates that newcomers can make contact and be integrated into the networks. Bullock et al. ${ }^{54}$ have highlighted the importance of multidisciplinary teams. Moreover, they emphasize the importance of providing rewards for teams participating in multidisciplinary research.

1. Zarco-Tejada, P. J., Hubbard, N. and Loudjani, P., Precision agriculture: an opportunity for EU farmers 2004-2020. Joint Research Centre (JRC) of the European Commission, Monitoring Agriculture ResourceS (MARS) Unit H04, European Union, 2014; http://www.europarl.europa.eu/studies (accessed on 22 July 2015). 
2. Bramley, R. G. V., Lesson from nearly 20 years of precision agriculture research, development, and adoption as a guide to its appropriate application. Crop Pasture Sci., 2009, 60(3), 197-217.

3. Bramley, R. G. V., Precision viticulture: managing vineyard variability for improved quality outcomes. In Understanding and Managing Wine Quality and Safety (ed. Reynolds, A. G.), Woodhead, UK, 2009.

4. Robert, P. C., Precision agriculture: a challenge for crop nutrition management. Plant Soil, 2002, 247(1), 143-149.

5. Srinivasan, A. (ed.), Handbook of Precision Agriculture: Principles and Application, The Haworth Press Inc, Binghamton, New York, USA, 2006.

6. Cox, G. J., Harris, H. D. and Pax, R., Development and testing of a prototype yield mapping system. Proc. Aust. Soc. Sugar Cane Technol., 1997, 19, 38-43.

7. Bramley, R. G. V. and Quabba, R. P., Opportunities for improving the management of sugarcane production through the adoption of precision agriculture - an Australian perspective. In Proceedings of the 24th Congress of the International Society. Sugar Cane Technology, Brisbane, Australia, 17-21 September 2001.

8. Cook, S. E., Adams, M. L., Bramley, R. G. V. and Whelan, B. M., Australia. In Handbook of Precision Agriculture: Principles and Applications (ed. Srinivasan, A.), The Haworth Press Inc, Binghamton, New York, 2006, pp. 529-566.

9. Proffitt, T., Bramley, R., Lamb, D. and Winter, E., Precision viticulture - A new era in vineyard management and wine production. Can. J. Soil Sci., 2006, 82, 9-21.

10. Tisseyre, B., Ojeda, H. and Taylor, J., New technologies and methodologies for site-specific viticulture. J. Int. Sci. Vigne Vin., 2007, 41, 63-76.

11. Bramley, R. G. V. and Hamilton, R. P., Understanding variability in winegrape production systems. 1 . Within vineyard variation in yield over several vintages. Aust. J. Grape Wine Res., 2004, 10(1), $32-45$.

12. Bramley, R. G. V. and Hamilton. R. P., Terroir and precision viticulture: are they compatible? J. Int. Sci. Vigne. Vin., 2007, 41, $1-8$.

13. Griffin, T. W. and Lowenberg-DeBoer, J., Worldwide adoption and profitability of precision agriculture. Rev. Pol. Agric., 2005, 14, 20-38.

14. Bramley, R. G. V., Lanyon, D. M. and Panten, K., Whole-ofvineyard experimentation - an improved basis for knowledge generation and decision-making. In Proceedings of the 5th European Conference on Precision Agriculture (ed. Stafford, J. V.), Wageningen Academic Publishers, The Netherlands, 2005, pp. 883-890.

15. Zaman, Q. U. and Schumann, A. W., Performance of an ultrasonic tree volume measurement system in commercial citrus groves. Precis. Agric., 2005, 6(15), 467-480.

16. Zaman, Q. U. and Schumann, A. W., Nutrient management zones for citrus based on variation in soil properties and tree performance. Precis. Agric., 2006, 7(1), 45-63.

17. Stoorvogel, J. and Bouma, J., Precision agriculture: the solution to control nutrient emissions? In Proceedings of the 5th European Conference on Precision Agriculture (ed. Stafford, J. V.), Wageningen Academic Publishers, The Netherlands, 2005, pp. 47-55.

18. Blackmore, S., Precision farming: a dynamic process. In Proceedings of the 6th International Conference on Precision Agriculture and Other Precision Resources Management. Minneapolis, Minnesota (eds Robert, P. C., Rust, R. H. and Larso, W. E.), ASA-CSASSSA, Madison, WI, USA, 2003, pp. 84-104.

19. Blackmore, S., Griepentrog, H., Pedersen, S. and Fountas, S., Europe. In Handbook of Precision Agriculture: Principles and Applications (ed. Srinivasan, A.), The Haworth Press Inc, Binghamton, New York, USA, 2006, pp. 567-613.
20. Zhang, M., Zhihao, Q. and Xue, L., Remote sensed spectral imagery to detect late blight in field tomatoes. Precis. Agric., 2005, 6(6), 489-508.

21. Praat, J. P., Bollen, F., Dewar, D. and Yule, I., Product tracking for profit. In 'Precision Tools for Improving Land Management. FLRC Occasional report No. 14 (eds Currie, L. D. and Loganathan, P.), Fertilizer and Lime Research Centre, Massey University, Palmerston North, New Zealand, 2001, pp. 107-113.

22. Praat, J. P., Bollen, A. F. and Mowatt, A., Characterising spatial variation in quality. Acta Hortic., 2007, 753, 305-316.

23. Bramley, R. G. V., Cook, S. E. and McMahon, G. G., Precision agriculture - what can it offer the Australian sugar industry? In Proceeding of a Workshop, CSIRO Land and Water, Townsville, 10-12 June 1997, ISBN 0643060480.

24. Swinton, S. M. and Lowenberg-DeBoer, J., Evaluating the profitability of site-pecific farming. J. Prod. Agric., 1998, 11(4), 439446.

25. Pannell, D. J., Marshall, G. R., Barr, N., Curtis, A., Vanclay, F. and Wilkinson, R., Understanding and promoting adoption of conservation practices by rural landholders. Aust. J. Exp. Agric., 2006, 46, 1407-1424.

26. Godwin, R. J., Richards, T. E., Wood, G. A., Welsh, J. P. and Knight, S. M., An economic analysis of the potential for precision farming in UK cereal production. Biosyst. Eng., 2003, 84(4), 533545.

27. Bramley, R. G. V., Proffitt, A. P. B., Hinze, C. J., Pearse, B. and Hamilton, R. P., Generating benefits from precision viticulture through selective harvesting. In Proceedings of the 5th European Conference on Precision Agriculture (ed. Stafford, J. V.), Wageningen Academic Publishers, The Netherlands, 2005, pp. 891-898.

28. Bramley, R. G. V. and Hamilton, R. P., Hitting the zone-making viticulture more precise. In Proceedings of the 12th Australian Wine Industry Technical Conference (eds Blair, R. J., Williams, P. J. and Pretorius, I. S.), 2005, pp. 57-61.

29. Vain, P., Trends in GM crop, food and feed safety literature. Nature Biotechnol., 2007, 25(16), 624-626.

30. Lanza, E. and Svendsen, B. A., Tell me who you are and I might be able to tell you what language(s) you speak: social network analysis, multilingualism, and identity. Int. J. Biling., 2007, 11(3), 275-300.

31. Ho, Y. S., Bibliometric analysis of adsorption technology in environmental science. J. Environ. Protect. Sci., 2007, 1, 1-11.

32. Chiu, W. T. and Ho, Y. S., Bibliometric analysis of tsunami research. Scientometrics, 2007, 73, 3-17.

33. Aleixandre, J. L., Aleixandre-Tudó, J. L., Bolaños, M. and Aleixandre-Benavent, R., Mapping scientific research on wine and health. J. Agric. Food Chem., 2013, 61(49), 11871-11880.

34. Batagelj, V. and Mrvar, A., Pajek: analysis and visualization of large networks. Lect. Notes Comput. Sci., 2002, 2265, 477478.

35. Dudnik, N. S., Thormann, L. and Hodgkin, T., The extent and use of plant genetic resources in research - a literature survey. Crop Sci., 2001, 41, 6-10.

36. Dalpe, R., Bibliometric analysis of biotechnology. Scientometrics, 2002, 55, 189-213.

37. Vain, P., Plant transgenic science knowledge. Nature Biotechnol., 2005, 23(11), 1348-1349.

38. Quixabeira, V. B. L., Nabout, J. C. and Rodrigues, F. M., Trends in genetic literature with use of flow cytometry. Cytometry, 2010, 77A(3), 207-210.

39. Leonidou, C. N. and Leonidou, L. C., Research into environmental marketing/management: a bibliographic analysis. Eur. J. Market, 2011, 45(1/2), 68-103.

40. Queiroz, J. C. B., Vieira, T. O., Araujo, P. P., Matos, F. A., Amin, M. M. and Salame, C. W., Three-dimensional geostatistical estimation of soil units: a case study from Capitao Pocinho, Para, Brazil. Soils Rocks, 2007, 40, 187-194. 
41. Guo, K., Liu, Y. F., Zeng, C., Chen, Y. Y. and Wei, X. J., Global research on soil contamination from 1999 to 2012: a bibliometric analysis. Acta Agric. Scand., 2014, 64(5), 377-391.

42. Crisostomo, C., Bteich. M. R., Moschitz, H. and Pugliese, P., Organic farming policy in Portugal: analysis of the policy network. New Medit., 2012, 11(4), 27-30.

43. Kondo, T., Nanba, H., Takezawa, T. and Okumura, M., Technical trend analysis by analyzing research papers' titles. Lect. Notes Comput. Sci., 2011, 6562, 512-521.

44. Ferguson, R. S. and Lovell, S. T., Permaculture for agroecology: design, movement, practice, and worldview. A review. Agron. Sustain. Dev., 2014, 34, 251-274.

45. Dabbert, S., Häring, A. M. and Zanoli, R., Organic Farming. Policies and Prospects, Zed Books, London, UK, 2003.

46. Cañas-Guerrero, I., Mazarrón, F. R., Pou-Merina, A., CallejaPerucho, C. and Díaz-Rubio, G., Bibliometric analysis of research activity in the 'agronomy' category from the Web of Science, 1997-2011. Eur. J. Agron., 2013, 50, 19-28.

47. de Aquino, R. E., Campos, M. C. C., Marques, J., de Oliveira, I A., Mantovaneli, B. C. and Soares, M. D. R., Geostatistics in assessment of physical properties in a latossolo (oxisol) under native forest and grassland in Manicore, Amazonas, Brazil. Rev. Bras. Ciênc. Solo, 2014, 38, 397-406.

48. de Aquino, R. E., Campos, M. C. C., Soares, M. D. R., de Oliveira, I. A., Franciscon, U. and Silva, D. M. P., Chemical soil attributes evaluated by multivariate techniques and geostatistics in the area with agroforestry and sugarcane in Humaita, AM, Brazil. BioScience J., 2016, 32, 61-72.
49. Righini, R. and Grossi Gallegos, H., Utilización preliminar de información GOES y métodos geoestadísticos para la evaluación del recurso solar en Brasil. Avances en Energías Renovables y Medio Ambiente, 2001, 5, 19-24.

50. Ferreira, A. B. et al., A streamlined approach by a combination of bioindication and geostatistical methods for assessing air contaminants and their effects on human health in industrialized areas: a case study in Southern Brazil. Front. Plant. Sci., 2017, 8, 1557.

51. Konur, O., The scientometric evaluation of the research on the production of bioenergy from biomass. Biomass Bioenerg., 2012, $47,504-515$.

52. Vandermeulen, A. V., Prins, W. B. S., Nolte, A. G. and Van Huylenbroeck, How to measure the size of a bio-based economy: evidence from Flanders. Biomass Bioenerg., 2011, 35(10), 43684375.

53. Meho, L. I. and Yang, K., Impact of data sources on citation counts and rankings of LIS faculty: web of science versus Scopus and Google Scholar. J. Am. Soc. Inf. Sci. Technol., 2007, 58(13), 2105-2125.

54. Bullock, D. S., Kitchen, N. and Bullock, D. G., Multidisciplinary teams: a necessity for research in precision agriculture systems. Crop Sci., 2007, 47, 1765-1769.

Received 28 March 2018; revised accepted 10 May 2018

doi: $10.18520 / \mathrm{cs} / \mathrm{v} 115 / \mathrm{i} 9 / 1653-1667$ 